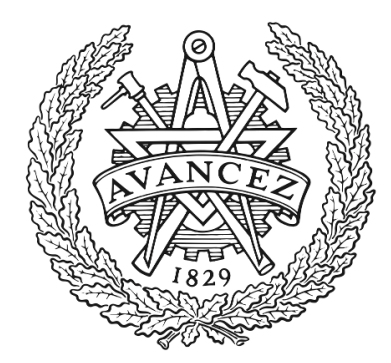

\title{
CHALMERS
}

UNIVERSITY OF TECHNOLOGY

\section{Introducing the Journal of English-Medium Instruction}

Downloaded from: https://research.chalmers.se, 2023-04-26 09:55 UTC

Citation for the original published paper (version of record):

Pecorari, D., Malmström, H. (2022). Introducing the Journal of English-Medium Instruction. Journal of English-Medium Instruction, 1(1): 1-6

N.B. When citing this work, cite the original published paper. 


\section{Introducing the Journal of English-Medium Instruction}

Diane Pecorari, City University of Hong Kong

Hans Malmström, Chalmers University of Technology

English-medium instruction (EMI) is a global and expanding phenomenon driven by a number of factors which have been so thoroughly described elsewhere (e.g., Coleman, 2006; Macaro, 2018; Richards \& Pun, 2021) as to require no further discussion here. The growth of EMI has raised a plethora of questions and given rise to an increasing body of research literature, as indicated by two recent systematic reviews (Macaro et al., 2018; Molino et al., forthcoming). These reviews establish that research interest in the topic has exhibited marked, recent growth (Molino et al. restricted their focus to five European countries, but nonetheless found over 200 relevant publications only in the last decade).

EMI by its very nature straddles a broad range of research areas. Much of the existing work on EMI falls within the areas of (applied) linguistics or language pedagogy, but questions related to EMI impinge upon numerous other subject areas. EMI research has the potential to inform areas ranging from the pedagogy of "content" subjects to educational policy. The purpose of this new journal is to provide a natural home for this multidisciplinary research topic.

Definitions of EMI typically include four elements:

1. English is the language used for instructional purposes.

2. English is not itself the subject being taught.

3. Language development is not a primary intended outcome.

4. For most participants in the setting, English is a second language (L2).

(Pecorari \& Malmström, 2018, p. 499)

These parameters circumscribe a varied and complex set of pedagogical settings, and it is this broad understanding of EMI which this journal intends to capture. For instance, although the term EMI is frequently applied in settings where English is an L2 (cf. Dearden, 2014, p. 2), questions of relevance to EMI may arise in contexts where it is a first language (L1), e.g., in Anglophone educational settings involving a significant proportion of speakers of other languages. Similarly, although Macaro (2018) rightly distinguishes EMI from content and language integrated learning, the two approaches have the potential to inform each other. The same observation holds true for EMI and English as a foreign language (EFL) research (cf. Coxhead \& Boutorwick, 2018). While maintaining a clear focus on EMI, the Journal of English-Medium Instruction will welcome contributions which advance research into the topic from broad and diverse perspectives.

The contributions to this inaugural issue of JEMI all embody this broader understanding of EMI and speak to a varied group of stakeholders, including researchers in EMI and related fields, and practitioners in contexts of EMI, e.g., teachers, students, and university management. The authors of these contributions were invited by virtue of their expertise in six areas central to EMI: language policy, multilingualism, English language teaching, teacher preparation and (higher) education pedagogy, and assessment. The authors were encouraged to examine their topics from the point of view of three different perspectives/questions: (i) Where are we now?, i.e., what is the state of existing research in the relevant area; (ii) Where should we go next?, or what should be on the research agenda for future work on the topic; (iii) and finally, the third part of each paper suggests how research findings on the topic can be delivered to end users such as learners, teachers, or policy makers, answering the question How 
This is the pre-print final version of the text. To view the published text (free copy access) go to:

https://benjamins.com/catalog/jemi.1.1

do we put it into practice? Authors were given considerable latitude to interpret these prompts as they saw fit.

The first paper of this issue - "Language policy and planning for English medium instruction in higher education" - has been authored by Amy Wanyue Ou (University of Gothenburg), Francis M. Hult (University of Maryland, Baltimore County), and Michelle Mingyue Gu (The Education University of Hong Kong). Following a review of EMI policy research in different higher education contexts, addressing inter alia, issues like English native-speakerism, English monolingualism, and language education, the author team advocates a stronger connection between institutional policymaking, individual appropriation of policy, and stakeholder needs "on the ground." To this end they put forward an idea for an "ecological framework" and a set of reflective question prompts which could help shape EMI policy in higher education.

In their paper "Towards multilingualism in English-medium higher education: A student perspective" Emma Dafouz (Complutense University of Madrid) and Ute Smit (University of Vienna) adopt a similar "on the ground" perspective focusing on students and their experiences in EMI. By drawing on the concepts English Medium Education in Multilingual University Settings (EMEMUS) and ROAD-MAPPING the authors argue for why EMI constitutes sites of multilingual engagement. Their literature review also emphasises students, and the review is used to construe four scenarios of current EMI research foregrounding different student groups and takes on multilingualism; subsequently, these same scenarios are used to highlight dimensions of multilingualism in English-medium higher education in need of further research.

In the contribution by David Lasagabaster (University of the Basque Country) the focus is shifted from students to teachers. His paper, entitled "Teacher preparedness for English-medium instruction," highlights the dearth of training and support for pre-service and in-service EMI teachers to help them function in what is (standardly) an English L2 teaching and learning context, and the ensuing consequences for EMI. According to Lasagabaster, teacher preparedness is a central issue which should be foregrounded in EMI implementation and, to this end, significantly more research is needed; for example, relating to (i) which competencies EMI teachers require and how they could be appropriately certified; (ii) the interface between language and pedagogy in EMI; and (iii) strategies for fostering student participation, engagement and interaction in EMI.

The paper "Teacher development to mediate global citizenship in English-medium education contexts," authored by Jennifer Valcke (Karolinska Institute), Nashwa Nashaat Sobhy (Polytechnic University of València), Davinia Sánchez-García (Complutense University of Madrid), Julie Walaszczyk (University of Mons), touches on similar issues relating to teaching in contexts of EMI. Valcke et al. highlight how continuous professional development initiatives for teachers - featuring issues such as inclusive and equitable quality education, transdisciplinary approaches to teaching, dialogic teaching and learning, and digitalization - can address emerging global teaching and learning competences critical for quality in EMI. To this end, the authors propose a model for continuous professional development, highlighting the connection between English-Medium Education and global citizenship education.

Jim McKinley (University College London Institute of Education) and Heath Rose (University of Oxford) address the critically important interface between language, language support and learning in EMI in their contribution "English language teaching and EMI: Putting research into practice." Acknowledging the growing body of research that highlights linguistic challenges faced by students in EMI, the authors discuss how research in (and research-informed advice stemming from) English for Academic Purposes 
and English for Specific Purposes can enhance the EMI experience, at least in the many higher education contexts where EMI is in its infancy and where research has confirmed that language related challenges create potential barriers for students' learning.

The final article - "Assessment and English as a medium of instruction: Challenges and opportunities" addresses the dearth of research into assessment in EMI. Aided by theories in Critical Language Testing, Kristina Hultgren (The Open University, UK), Nathaniel Owen (Oxford University Press) and Prithvi Shrestha (The Open University, UK), Maria Kuteeva (Stockholm University) and Špela Mežek (Stockholms universitet) map an assessment landscape fraught with complexity and ask what, who, how and why assessment should take place in EMI. In looking to the future, the authors propose a reconceptualization of assessment in EMI where the important role of language is emphasized.

The issue concludes with "A research agenda for English-medium instruction: Conversation with scholars at the research fronts," a collection of interviews curated by Pramod Sah (University of British Columbia). Sah, an early-career scholar who is likely to engage with the evolving field for some time in the future, conducted interviews with nine scholars (representing different geographical contexts) offering their views regarding the research agenda(s) in EMI. His conclusion highlights several strands of EMI research that deserve our attention as the field moves forward, including (i) the nature of the medium of instruction; (ii) long-term impact of EMI; (iii) effectiveness of EMI at different levels of education; (iv) EMI classroom practices, agency and investment; (v) political economy, governance, and policy making around EMI; (vi) critical perspectives on EMI; (vii) EMI teacher knowledge; (viii) assessment in EMI.

No doubt these topics will be addressed in future issues of this journal, and we look forward to seeing the journal serve as a vehicle drawing together work on these diverse strands. In addition to that broad objective, we have three more specific ambitions for JEMI and the work published in it.

First, we hope that it will promote reflection and clarity on the relationship of EMI to other multilingual pedagogies. The need for this is illustrated by the wealth of alternative terminology for the phenomenon. The fact that scholars develop and adopt labels such as ICLHE (Integrating Language and Content in Higher Education; Valcke \& Wilkinson, 2017) or EMEMUS (English-Medium Education in Multilingual University Settings; Dafouz \& Smit, 2016) to refer to phenomena broadly similar to EMI is a signal that researchers in this area perceive that there is scope to clarify its parameters. We look forward to seeing that project of clarification unfold within the pages of JEMI.

A second ambition is to see researchers from a broad range of academic disciplines publishing their work in the journal. This includes, most decidedly, the "content" teachers from across the curriculum who are involved in the direct delivery of EMI. Content teachers do not always feel entitled to assume the role of language specialist in the EMI classroom, and yet when they do attend to language, students perceive it as beneficial (Doiz \& Lasagabaster, 2021). Garnering their participation in this forum, and in EMI research generally, may go some way to reducing their reluctance to engage with language issues in the classroom.

This would make a significant contribution to our third ambition for the journal: seeing that the research published in it achieves the very real potential which EMI has to be impactful in broader society. Two observations demonstrate the importance of realising impact. On one hand, the rapid expansion in the adoption of EMI is continuing apace (this trend is evidenced, for example, in several of the contributions in Wilkinson \& Gabriels, 2021, and in Malmström \& Pecorari, 2021). In other words, there is ever more 
EMI around. At the same time, some aspects of it are perceived by at least some actors as problematic (e.g., Rose, 2021; van Parijs, 2021). It is important that research on the topic goes beyond illuminating the situation and delivers solutions for the problems which (can) accompany EMI.

We welcome the engagement of the scholarly community in realising these ambitions.

\section{References}

Coleman, J. A. (2006). English-medium teaching in European higher education. Language Teaching, 39(01), 1-14. https://doi.org/10.1017/S026144480600320X

Coxhead, A., \& Boutorwick, T. J. (2018). Longitudinal Vocabulary Development in an EMI International School Context: Learners and Texts in EAL, Maths, and Science. TESOL Quarterly, 52(3), 588-610. https://doi.org/10.1002/tesq.450

Dafouz, E., \& Smit, U. (2016). Towards a dynamic conceptual framework for English-medium education in multilingual university settings. Applied Linguistics, 37(3), 397-415. https://doi.org/10.1093/applin/amu034

Dearden, J. (2014). English as a medium of instruction: A growing global phenomenon. British Council. Doiz, A., \& Lasagabaster, D. (2021). Analysing EMI teachers' and students' talk about language and language use. In D. Lasagabaster \& A. Doiz (Eds.), Language use in English-medium instruction at university: International perspectives on teacher practice (pp. 34-55). Routledge.

Macaro, E. (2018). English medium instruction. Oxford University Press.

Macaro, E., Curle, S., Pun, J., An, J., \& Dearden, J. (2018). A systematic review of English medium instruction in higher education. Language Teaching, 51(01), 36-76. https://doi.org/10.1017/S0261444817000350

Malmström, H., \& Pecorari, D. (2021). Språkval och internationalisering: svenskans och engelskans roll inom forskning och högre utbildning. [Language choice and internationalisation: The roles of Swedish and English in research and higher education]. Språkrådet.

Molino, A., Dimova, S., Kling, J., \& Larsen, S. (forthcoming). The evolution of EMI research in European higher education. Routledge.

Pecorari, D., \& Malmström, H. (2018). At the Crossroads of TESOL and English Medium Instruction. TESOL Quarterly, 52(3), 497-515. https://doi.org/10.1002/tesq.470

Richards, J., \& Pun, J. (2021). A typology of English-medium instruction. RELC Journal, 003368822096858. https://doi.org/10.1177/0033688220968584

Rose, H. (2021). Students' language-related challenges of studying through English: What EMI teachers can do. In D. Lasagabaster \& A. Doiz (Eds.), Language use in English-medium instruction at university: International perspectives on teacher practice (pp. 145-166). Routledge.

Van Parijs, P. (2021). Englishization as trap and lifeline. In R. Wilkinsson \& R. Gabriels (Eds.), The Englishization of higher education in Europe (pp. 355-368). Amsterdam University Press.

Valcke, J., \& Wilkinson, R. (2017). Introduction: ICLHE, professional practice, disruption and quality. In J. Valcke \& R. Wilkinson (Eds.), Integrating Content and Language in Higher Education (pp. 15-24). Peter Lang.

Wilkinson, R., \& Gabriels, R. (2021). The Englishization of higher education in Europe. Amsterdam University Press. 